\title{
CORRECTION
}

View Article Online

View Journal | View Issue

\section{Correction: $\mathrm{Fe}(\mathrm{II})_{(\mathrm{aq})}$ uptake of $\mathrm{Mg}(\mathrm{II})-\mathrm{Al}(\mathrm{III}) / \mathrm{Fe}(\mathrm{III})-$ $\mathrm{SO}_{4} / \mathrm{CO}_{3} \mathrm{HTLCs}$ under alkaline conditions: adsorption and solid state transformation mechanisms}

Cite this: RSC Adv., 2014, 4, 60112

DOI: $10.1039 / c 4 r a 90039 a$

www.rsc.org/advances

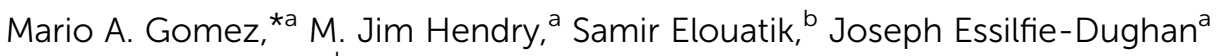
and Susanta Paikaray ${ }^{\mathrm{b}}$

Correction for ' $\mathrm{Fe}(\mathrm{II})_{(\mathrm{aq})}$ uptake of $\mathrm{Mg}$ (II)- $\mathrm{Al}(\mathrm{III}) / \mathrm{Fe}(\mathrm{III})-\mathrm{SO}_{4} / \mathrm{CO}_{3}$ HTLCs under alkaline conditions: adsorption and solid state transformation mechanisms' by Mario A. Gomez et al., RSC Adv., 2014, 4, 54973-54988.

The panels in Fig. 1 and 5 are incorrectly labelled. The correctly labelled figures are as follows:

(a)

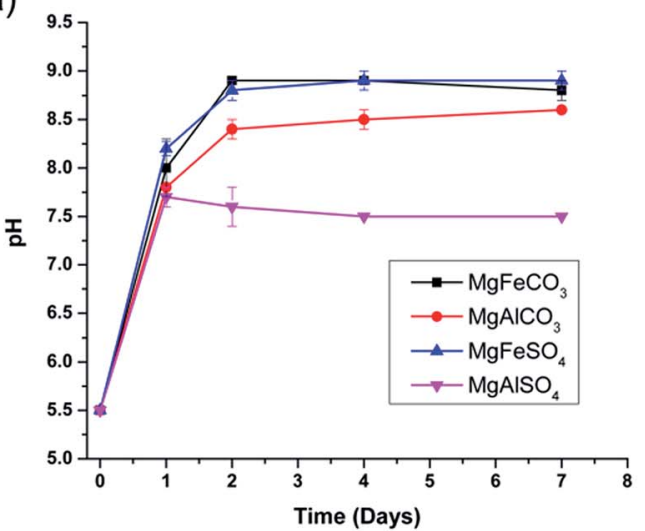

(b)

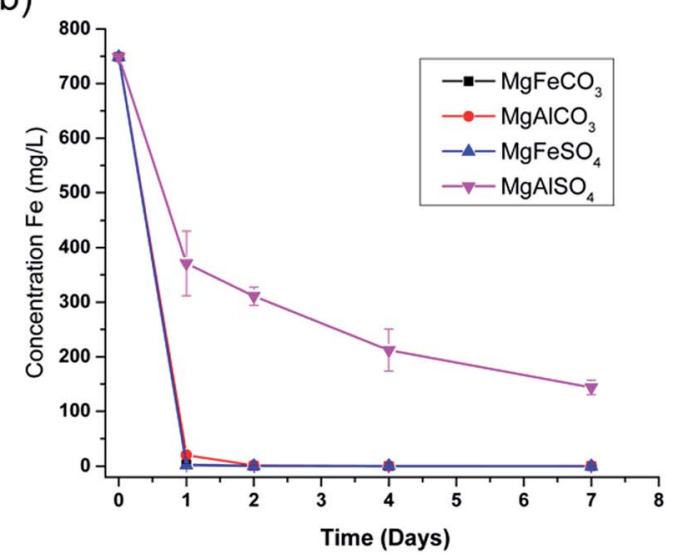

(c)

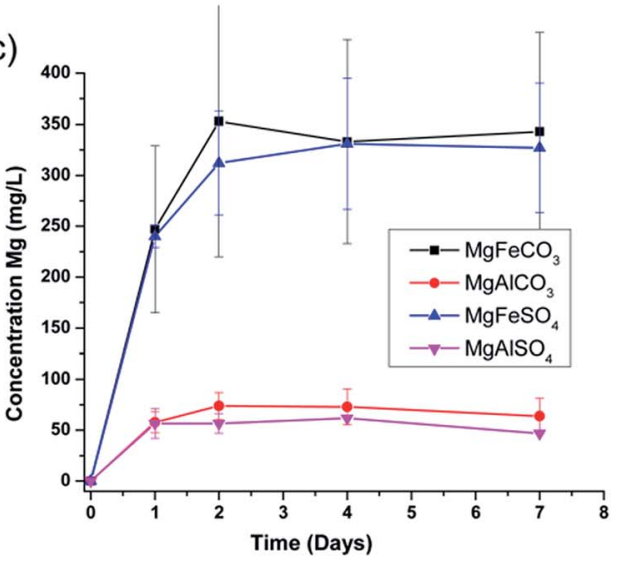

Fig. 1 Profiles of $\mathrm{pH}$ and leachability of the total aqueous Fe and $\mathrm{Mg}$ as a function of time for tests conducted at $\mathrm{pH} 8$ for 7 days with $10 \mathrm{mM}$ $\mathrm{Fe}\left({ }^{\prime \prime}\right)_{(\text {aq) }}$. Time 0 days represents conditions before $\mathrm{Mg}(॥)-\mathrm{Al}(\mathrm{(I)}) / \mathrm{Fe}(\mathrm{II})-\mathrm{CO}_{3} / \mathrm{SO}_{4} \mathrm{HTLC}$ solids were added. Concentration units for $(\mathrm{Fe})$ and $(\mathrm{Mg})$ are $\mathrm{mg} \mathrm{L}^{-1}$. Values reported are the average and standard deviation (error bars) of duplicate tests. Individual test data are provided in the ESI. $\dagger$

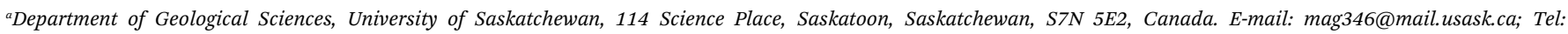
+1-306-2616246

${ }^{b}$ Department of Chemistry, University of Montreal, C.P. 6128, Succursale Centre-ville, Montreal, Quebec, H3C 3J7, Canada 
(a)

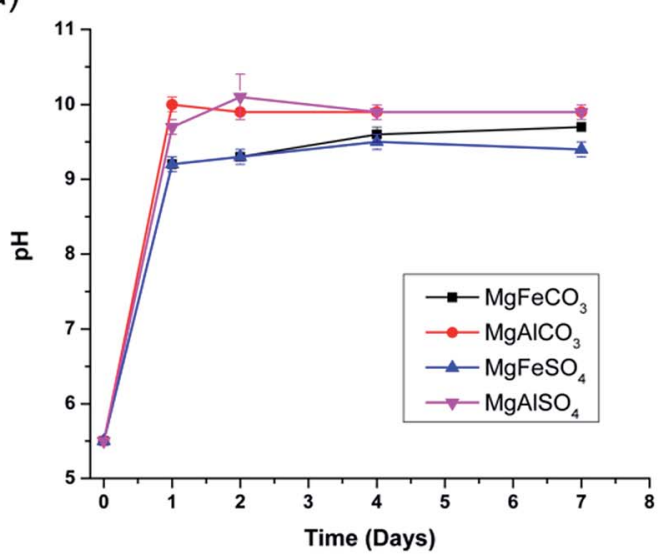

(b)

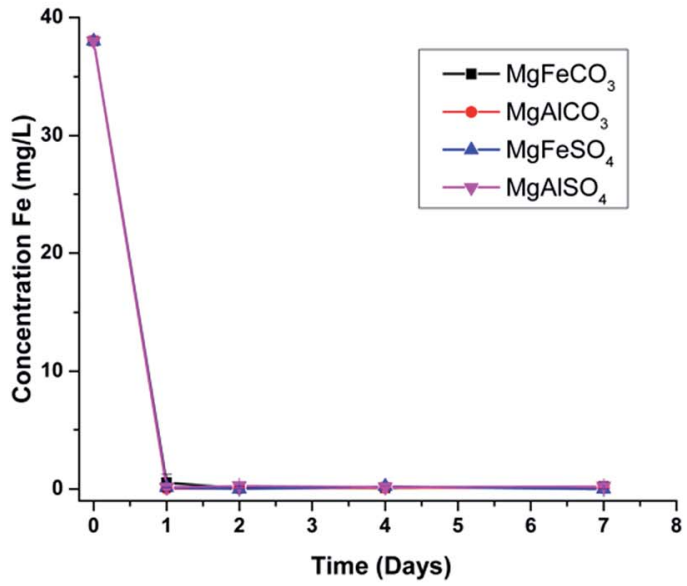

(c)

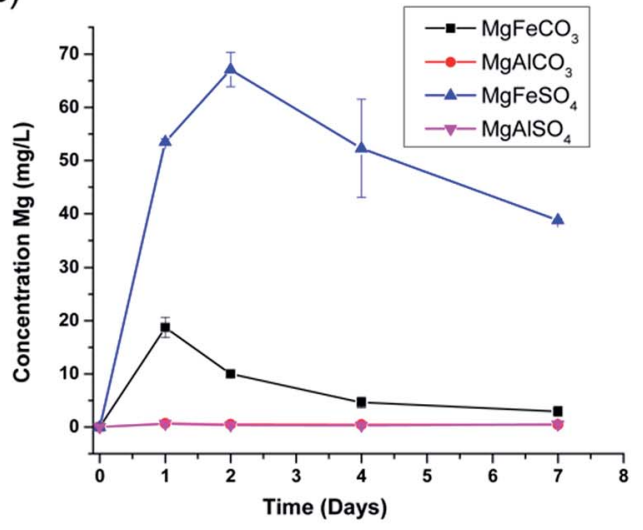

Fig. 5 Profiles of $\mathrm{pH}$ and leachability of the total aqueous $\mathrm{Fe}$ and $\mathrm{Mg}$ as a function of time for tests conducted at $\mathrm{pH} 10$ for 7 days with $0.5 \mathrm{mM}$

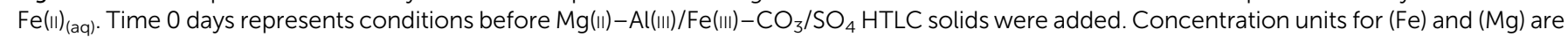
$\mathrm{mg} \mathrm{L}^{-1}$. Values reported are the average and standard deviation (error bars) of duplicate tests. Individual test data are provided in the ESI. $\dagger$

The Royal Society of Chemistry apologizes for these errors and any consequent inconvenience to authors and readers. 